\title{
OTIMIZAÇÃO DE PROCESSOS DE OBTENÇÃO DE QUITOSANA A PARTIR DE RESÍDUO DA CARCINICULTURA PARA APLICAÇÕES AMBIENTAIS ${ }^{1}$
}

\author{
Andressa Caroline Neves ${ }^{2}$, Rodolfo de Andrade Schaffner ${ }^{3}$, Cristie Luis Kugelmeier ${ }^{4}$, Angela Maria Wiest ${ }^{5}$, \\ Mabel Karina Arantes ${ }^{6}$
}

${ }^{1}$ Aceito para publicação, $1^{\circ}$ trimestre de 2013.

${ }^{2}$ Graduando de Tecnologia em Biotecnologia - Setor Palotina - UFPR.

${ }^{3}$ Graduando de Tecnologia em Biocombustíveis- Setor Palotina - UFPR.

${ }^{4}$ Graduando de Tecnologia em Biocombustíveis- Setor Palotina - UFPR.

${ }^{5}$ Graduando de Tecnologia em Biocombustíveis- Setor Palotina - UFPR.

${ }^{6}$ Graduação em Química na Universidade Federal de São Carlos - SP.

Mestrado em Biotecnologia na Universidade Federal de São Carlos - SP.

Docente da Universidade Federal do Paraná (UFPR) - Setor- Palotina/PR.

Palavras-chave: quitina, quitosana, desacetilação.

\section{Resumo}

Neste trabalho abordou-se a utilização de um resíduo de carcinicultura, a carapaça de camarão, como fonte de quitina, precursor do biopolímero quitosana para o qual diversas aplicações têm sido estudadas e executadas nas mais diversas áreas, incluindo a ambiental, com destaque para o tratamento de efluentes para remoção de metais e corantes, biorremediação, entre outros destinos. Quitina foi preparada por desmineralização e desproteinação química, por métodos que demonstraram eficácia maior que 99\%. Foram testados diferentes métodos de desacetilação visando à otimização do processo o que compreende menor geração de resíduos, menor tempo e custo reacional e obtenção de alto grau de desacetilação. Resultados preliminares revelam valores de grau médio de desacetilaçao entre 0 e $79 \%$ e apontam parâmetros importantes na etapa de desacetilação que ainda precisam ser variados e avaliados a fim de definir o melhor método, a ser utilizado em ensaios com aumento de escala.

\section{Introdução}

Revista Brasileira de Energias Renováveis, v. 2, p. 34-47, 2013 
A carcinicultura ou criação de camarões em cativeiro, ramo de atividade dentro da aquicultura, ocupa lugar de destaque entre os produtos de origem aquática, sendo que da criação em cativeiro destes animais provém cerca de metade dos camarões consumidos no mundo [1]. Associado ao alto consumo de camarões no Brasil e no mundo está o problema ambiental da geração de resíduos, já que cerca de $40 \%$ da massa total industrializada do camarão é descartada na forma de resíduo sólido (carapaça, conteúdo protéico, etc.) durante o processamento do crustáceo, o que no Brasil promove o acúmulo de milhares de toneladas de resíduos por ano [2]. De uma forma geral, os municípios brasileiros não possuem coleta seletiva, nem aterros sanitários disponíveis para a correta disposição destes resíduos isto contribui para o aumento da poluição ambiental, possível contaminação dos lençóis freáticos e desenvolvimento de doenças.

Os resíduos da carcinicultura são compostos basicamente pela carapaça dos camarões que possuem altos teores de quitina (15-20\%), proteínas (25-40\%), sais inorgânicos (cinzas 40-55\%) e pigmentos carotenóides (cerca de 15\%), o que significa que ao invés de simplesmente descartar estes materiais pode-se buscar aproveitamento para tais componentes, minimizando os impactos ambientais do acúmulo de tais resíduos [3, 4].

A quitosana é um biopolímero obtido pela desacetilação alcalina da quitina, um dos polissacarídeos mais abundantes da natureza [5], composto por ligações $\beta(1 \rightarrow 4)$ de N- acetil D-glicosamina e encontrado em muitas espécies de animais marinhos e plantas inferiores, além de compor parede celular de leveduras e exoesqueleto de invertebrados como camarão, siri, caranguejos e insetos. No biopolímero quitina está presente nos grupos acetamida, caracterizados por resíduos de $\mathrm{R}-\mathrm{NHCOCH}_{3}$ que são removidos parcialmente na reação de desacetilação, gerando o biopolímero quitosana, em que predominam grupos amina, $\mathrm{R}-\mathrm{NH}_{2}$ (Figura 1). Quando esta desacetilação é maior que 50\%, o biopolímero torna-se solúvel em soluções aquosas ácidas e se comporta como um polieletrólito catiônico, devido à protonação dos grupos amina em presença de íons $\mathrm{H}^{+}$e tal característica identifica este material como quitosana e não mais quitina [3].

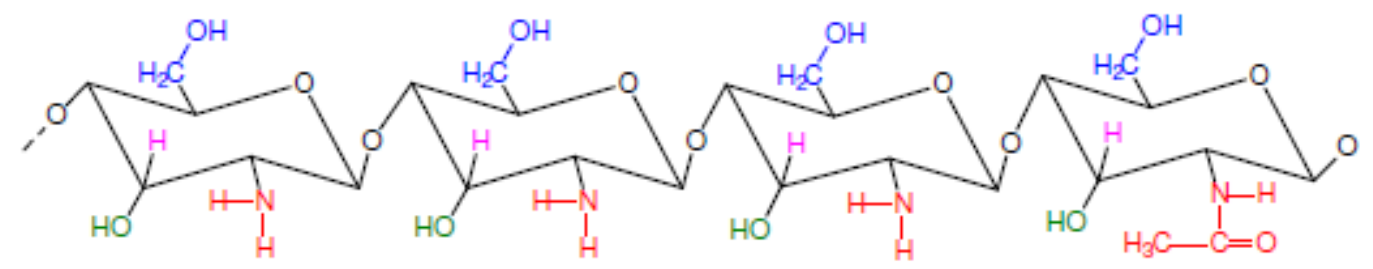

Figura 1: Representação da q uitosana, polissacarídeo com predominância de grupos amino (NH2) resultantes da desacetilação de grupos acetamida (-NHCOCH3) da quitina. 
Uma vez que quitosana é insolúvel em soluções aquosas que não sejam ácidas, uma importante aplicação de quitosana na área ambiental diz respeito à adsorção de metais pesados provenientes de resíduos industriais [Cd (II), $\mathrm{Cu}$ (II), $\mathrm{Cr}$ (III), $\mathrm{Pb}$ (II), $\mathrm{Zn}$ (II) $\mathrm{Ni}$ (II), $\mathrm{Hg}$ (II), U (VI) e V (IV)] devido à presença de grupos amino livres, além de reagir prontamente também com proteínas, polissacarídeos, vitaminas e sais minerais. A eficiência deste biopolímero em biorremediação tem sido estudada sob diversas formas (esferas, filmes, hidrogéis, outros), como suporte para imobilização de células comumente empregadas em biorremediação [6]. A biorremediação se destaca pela ampla gama de microrganismos que podem metabolizar muitos dos principais poluentes, além de não deixar resíduos ou subprodutos recalcitrantes, como geralmente ocorre com outras técnicas. A imobilização traz uma serie de vantagens, além de facilitar o controle do processo e dos microrganismos. A quitosana agrega várias características que o tornam um suporte ideal para imobilização de certos organismos. Destaca-se sua biodegradabilidade, lipofilicidade, capacidade de formar gel e microesferas, além de poder ser reticulado.

Além daquelas aplicações para as quais quitosana pura é adequada, muitas vezes é viável a modificação química de sua estrutura visando-se potencializar sua atividade. Cite-se, por exemplo, a obtenção de um sal quaternário de amônio para maior potencial de adsorção de corantes reativos de efluentes têxteis [7].

Embora quitina seja componente de numerosas fontes biológicas, a obtenção laboratorial e industrial deste biopolímero ocorre usualmente a partir de exoesqueletos de crustáceos, particularmente de camarão e caranguejo [3]. A carapaça de camarão é constituída por cerca de $20 \%$ em massa de quitina, o que a caracteriza como uma importante fonte natural deste biopolímero.

Diferentes métodos descritos na literatura são utilizados para extrair a quitina a partir da carapaça de camarão e dentre eles o método químico é amplamente o mais utilizado atualmente. Neste método as carapaças são lavadas, secas, trituradas, moídas e peneiradas, e o pó obtido é desmineralizado por tratamento com solução de ácido clorídrico, e posteriormente submetido à desproteinação e despigmentação, com soluções de hidróxido de sódio e hipoclorito de sódio ou água oxigenada, respectivamente [8]. O produto resultante destes tratamentos químicos consiste no biopolímero quitina, com baixíssimo conteúdo mineral e proteico e bastante despigmentado, e seguirá para o processo de desacetilação para obtenção da quitosana. 
A reação de desacetilação da quitina é estudada na literatura visando à obtenção de alto grau de desacetilação (GD) e baixa degradação do biopolímero, em um processo com tempo reacional, temperatura e custos reduzidos. Podem-se destacar neste sentido dois métodos, ambos utilizando reações de hidrólise básica: o método que emprega solução aquosa alcalina e outro que minimiza a presença de água, através de uso de solventes não aquosos para o preparo da solução alcalina. Nos dois casos são necessárias altas concentrações de base, em torno de $50 \%\left(\mathrm{mxm}^{-1}\right)$, temperaturas entre 80 e $120^{\circ} \mathrm{C}$ e tempos de refluxo variáveis entre 6 e 10 horas. Em nosso laboratório buscou-se avaliar e otimizar os métodos de isolamento de quitina e obtenção de quitosana relatados na literatura visando à definição do método de menor custo e tempo reacional, menor geração de resíduos (soluções ácidas e básicas) e demais variáveis que permitam a obtenção de quitosana com alto grau de desacetilação, para nos trabalhos futuros processar maiores quantidades de carapaça de camarão o obter quitosana em quantidade e qualidade para estudos de aplicabilidade deste biopolímero em áreas ambientais pertinentes.

\section{MATERIAL E MÉTODOS}

\section{-Isolamento De Quitina.}

Carapaças de camarão de água doce da espécie Macrobrachium rosenbergii foram limpas, secas e trituradas em moinho de bolas a seco até passagem completa em malha 250 mesh. Em seguida a desmineralização deste material foi conduzida com $100 \mathrm{~mL}$ de solução de $\mathrm{HCl}$ 0,55M para $10 \mathrm{~g}$ de carapaça, sob agitação constante e temperatura ambiente. Foram realizados dois ciclos com duração de15 minutos e um terceiro com duração de 1 hora, seguido do enxague com água destilada até pH neutro, sob filtração a vácuo. Este resíduo foi seco a $50^{\circ} \mathrm{C}$ por 24 horas para posterior desproteinação com solução de $\mathrm{NaOH} 0,3 \mathrm{M}$, sob agitação e temperatura de $80^{\circ} \mathrm{C}$, por três ciclos de 20 minutos de duração, seguidos do enxague com água destilada sob filtração a vácuo até $\mathrm{pH}$ neutro e secagem a $50^{\circ} \mathrm{C}$ por 24 horas.

\section{-Preparação De Quitosana.}

Foram empregados variações de dois métodos de desacetilaçao de quitina: método 1 - reação de desacetilação com solução de $\mathrm{NaOH}$ aquosa; método 2 - reação de desacetilaçao com solução de $\mathrm{KOH}$ não aquosa, com emprego de uma mistura do solvente etanol e monoetilenoglicol, método adaptado de Broussignac, 2010 [9]. Para o método 01 foram 
conduzidos ensaios sob refluxo com solução aquosa de $\mathrm{NaOH} 50 \%$ (m.v-1), à temperatura de $100^{\circ} \mathrm{C}$ com duração de 10 horas. A proporção de quitina e solução foi de 2,5\% (m.v-1).

Para o método 02 foram testadas soluções não aquosas com diferentes proporções de $\mathrm{KOH}$, etanol e monoetilenoglicol: Solução A: 5\% de KOH (mxm-1), 47\% de etanol (mxm-1) e $48 \%$ de monoetilenoglicol (mxm-1); Solução B: $15 \%$ de KOH (mxm-1), $42 \%$ de etanol (mxm-1) e $43 \%$ de monoetilenoglicol (mxm-1); Solução C: $27 \%$ de KOH (mxm-1), 22\% de etanol (mxm-1) e 51\% de monoetilenoglicol (mxm-1). Para as soluções A e B foram conduzidos refluxos por 6 horas a $87^{\circ} \mathrm{C}$ e para a solução $\mathrm{C}$ a temperatura manteve-se em $110^{\circ} \mathrm{C}$, com a mesma duração do refluxo. A proporção de quitina para volume de solução foi de 2,2 e 1 (\% m.v-1).

Para todos os métodos, depois de decorrido o tempo de refluxo o conteúdo insolúvel foi separado, lavado com água destilada até $\mathrm{pH}$ neutro sob filtração à vácuo e seco por $24 \mathrm{~h}$ a $50^{\circ} \mathrm{C}$.

\section{-Características Físico Químicas De Quitina e Quitosana.}

O teor de umidade de amostras de quitina e quitosana foram determinados por método gravimétrico. O conteúdo mineral de carapaça de camarão e a avaliação da eficiência do processo de desmineralização foram determinados por incineração em mufla a $700^{\circ} \mathrm{C}$, para amostras de carapaça de camarão antes e após o tratamento ácido, previamente seco a $110^{\circ} \mathrm{C}$. Utilizou-se ciclo de aquecimento de 2 horas até $700^{\circ} \mathrm{C}$, temperatura mantida por 2 horas. Determinou-se o teor de proteínas na carapaça de camarão desmineralizada e na quitina, após desproteinação, através de uma adaptação do método de Biureto, onde antes da etapa de reação com o reativo de Biureto procedeu-se a solubilização de proteínas, da carapaça ou da quitina, com $\mathrm{NaOH}$ 0,3M e com alíquota da fração solúvel seguiu-se a reação. Para determinação do grau médio de acetilação (GA) ou desacetilação (GD) utilizou-se método potenciométrico, adaptado de Santos, 2003 [10]: amostras de quitosana foram solubilizadas em ácido clorídrico 0,05 M, na proporção de 0,5\% (m.v-1) sob agitação por 24 horas e em seguida submetida à titulação condutimétrica com solução de $\mathrm{NaOH} 0,17 \mathrm{M}$. Os valores de condutância foram medidos a cada adição de $0,2 \mathrm{~mL}$ de titulante, em condutivímetro MS Tecnoton, célula AS405. A caracterização por espectroscopia na região do IV foi obtida em espectrofotômetro BomenMB-Series, com registros entre 4000 e $400 \mathrm{~cm}-1$, a partir de pastilhas contendo uma mistura da amostra com $\mathrm{KBr}$ na concentração de1\% (m.m-1). A resolução utilizada foi de $04 \mathrm{~cm}-1$ e os espectros foram obtidos com 21 varreduras. Uma vez 
que quitosana tem natureza higroscópica avaliou-se o teor de umidade de amostras obtidas pelos dois métodos de desacetilaçao, aquoso e não aquoso, através de método gravimétrico.

\section{RESULTADOS E DISCUSSÕES}

\section{- Isolamento De Quitina.}

O biopolímero quitina, precursor da quitosana, está incorporado ao exoesqueleto dos crustáceos juntamente com um alto conteúdo mineral e proteico, sendo que o teor de minerais é variável entre os crustáceos e de acordo com ambiente aquático (tanques de água doce ou água do mar). A análise elementar de diferentes crustáceos (lula, camarão, lagosta) demonstra essa variabilidade: segundo Tolaimate, 2003 [3], por exemplo, o valor é de 1,8\% para lula, $22 \%$ para camarão rosa, $36 \%$ lagosta. Deste modo, ao obter o resíduo carapaça de camarão e processá-lo para isolar quitina, espera-se remover um conteúdo mineral que varia de 20 a $30 \%$, aproximadamente, e também um conteúdo proteico que é próximo de 40\%. Estas etapas iniciais, desmineralização e desproteinação, precisam ser eficientes de tal forma que a quitina extraída seja praticamente isenta de conteúdo inorgânico e proteico. Neste trabalho, foram utilizados para desmineralização e desproteinação os métodos mais comuns citados na literatura pertinente: lavagens com $\mathrm{HCl} 0,55 \mathrm{M}$ e $\mathrm{NaOH} 0,3 \mathrm{M}$ e os resultados obtidos encontram-se na Tabela1.

No tratamento ácido para desmineralização do material observou-se uma forte efervescência ao adicionar a solução de $\mathrm{HCl}$, o que indica liberação de gás $\mathrm{CO} 2$, proveniente do alto conteúdo de carbonatos, principal componente mineral dos exoesqueletos de crustáceos, juntamente com os fosfatos. Sabe-se que a composição carbonato/fosfato varia de uma espécie para outra, mas a intensidade da evolução de gás durante o processo pode ser indicativo do conteúdo mineral em carbonatos [3].

Tabela 1: Resultados relacionados à desmineralização e desproteinação de carapaça de camarão

\begin{tabular}{|c|c|c|c|}
\cline { 2 - 4 } \multicolumn{1}{c|}{} & Carapaça triturada & $\begin{array}{c}\text { Após tratamento de } \\
\text { desmineralização }\end{array}$ & $\begin{array}{c}\text { Após tratamento de } \\
\text { desproteinação }\end{array}$ \\
\hline $\begin{array}{c}\text { Teor de umidade } \\
(\%)\end{array}$ & 9,6 & 9,9 & ---- \\
\hline $\begin{array}{c}\text { Perda em massa } \\
(\%)\end{array}$ & ----- & 34 & 42 \\
\hline Teor de cinzas $(\%)$ & 31 & $0-1$ & ---- \\
\hline Teor de proteínas & 42 & --- & $0-1$ \\
\hline
\end{tabular}

A avaliação da eficiência do processo de desmineralização por determinação do teor de cinzas mostrou que a metodologia empregada é eficaz, ao promover uma remoção de 99- 
$100 \%$ dos minerais (Tabela 1), de modo que os próximos ensaios terão por objetivo reduzir a utilização de $\mathrm{HCl}$, diminuindo a concentração da solução ou a razão massa de carapaça/ volume de solução, visando à redução de gastos e de resíduo gerado, desde que se mantenham os padrões aceitáveis para quitina comercial cujo teor mineral é cerca de 0,6\% [3].

Com relação à desproteinação da carapaça de camarão, sabe-se que a eficiência do método está relacionada à capacidade de a solução alcalina solubiliza proteínas estruturais, que compõem a carapaça. $\mathrm{O}$ uso de solução de $\mathrm{NaOH} 0,3 \mathrm{M}$ aliado a aquecimento de $80^{\circ} \mathrm{C}$ tem como finalidade desnaturar essas proteínas, separando-as na fração líquida. Os resultados obtidos em termos de perda de massa na etapa de desproteinação, de cerca de $40 \%$ coincidem com o teor proteico normalmente relatado na literatura, mas o teor proteico antes e após este tratamento alcalino pode ser determinado analiticamente por adaptações aos métodos do Biureto [11], Khjeldahl [12], Adler-Nissen [13], entre outros. No presente trabalho utilizou-se uma adaptação ao método do Biureto, e os resultados obtidos concordaram com a literatura com relação ao teor de proteínas em carapaça de camarão, relatados como cerca de $40 \%$. Além disso, observou-se que o tratamento alcalino para remoção de proteínas é eficiente, uma vez que o teor proteico foi inferior a $1 \%$ (Tabela 1 ).

A diferença entre a perda de massa no processo de desmineralização e o teor real de minerais perdidos nesta etapa (Tabela 1), determinado por incineração em mufla, deve-se às lavagens e filtrações necessárias para deixar o material com pH neutro, o que acarreta ao processo perda de cerca de 2-3\% em rendimento, nesta etapa. Essa mesma perda se reproduz após a desproteinação, que também requer lavagens até pH neutro. Observa-se ainda que o rendimento final após estas duas etapas é de cerca de $24 \%$, o que coincide com o teor de quitina normalmente relatado para carapaças de camarão na literatura pertinente, em torno de $22 \%$.

\section{- Obtenção e Caracterização De Quitosana.}

O material de partida para a etapa de obtenção de quitosana é a quitina isolada após os procedimentos de desmineralização e desproteinação. A desacetilação consiste na remoção de grupos acetil $\left(-\mathrm{COCH}_{3}\right)$ das funções acetamida $\left(-\mathrm{NHCOCH}_{3}\right)$ presentes no biopolímero quitina, de modo a deixar grupos amina $\left(-\mathrm{NH}_{2}\right)$ livres no biopolímero, quitosana. $\mathrm{O}$ número de grupos aminas livres na quitosana é proporcional ao parâmetro conhecido como grau de desacetilaçao e quanto maior for este valor, melhores serão as propriedades que resultam da presença de grupos amina, sendo a principal propriedade a solubilidade em soluções aquosas ácidas, que está relacionada com a quantidade de grupos amino protonados $\left(-\mathrm{NH}_{3}{ }^{+}\right)$na cadeia 
polimérica. Quanto maior a quantidade destes grupos, maior a repulsão eletrostática entre as cadeias e também maior a solvatação em água. Segundo Macquarrie \& Hardy, 2005 [14] não há um valor percentual de grau de desacetilação pelo qual se possa definir o biopolímero como quitina ou quitosana, entretanto quitosanas comerciais possuem GD determinado e geralmente inferior a 95\%. Valores superiores de GD são obtidos por técnicas complementares e processos sofisticados de desacetilação, a custos elevados, e estes produtos são destinados a aplicações biomédicas [15].

Além do aspecto da solubilidade em soluções aquosas ácidas, a presença dos grupos amina na quitosana é aspecto chave para suas mais variadas aplicações: em catálise, por exemplo, busca-se funcionalizar estes grupos básicos $\left(-\mathrm{NH}_{2}\right)$ tornando-os sítios ativos para reações, como por exemplo, através de complexos quitosana-metal $[14,16]$. Sua natureza solúvel quando catiônica também é interessante para atração eletrostática de compostos aniônicos, incluindo ânions metálicos ou corantes aniônicos na área de tratamento de efluentes [17].

Fica evidente, portanto que a principal característica do processo de desacetilação de quitina adotado deve ser o alto grau de desacetilação (GD) da quitosana produzida. Embora haja outras características associadas ao método de desacetilação, como por exemplo, a degradação do biopolímero de acordo com o tempo e temperatura de reação, a primeira avaliação a se fazer é quanto ao GD.

No presente trabalho esta é a primeira abordagem para fins de comparação entre os métodos de desacetilação testados, sendo que o grau de desacetilação médio (GD) foi determinado por titulação condutimétrica, em triplicata, para todos os experimentos de desacetilação. São exibidas na Figura 2 as curvas de titulação representativas dos resultados obtidos até o momento através do método utilizando solução aquosa alcalina e refluxo de 10 horas, aqui denominado método 1 e para uma das variações do método 2 (não aquoso, refluxo de 6 horas), denominado método 2C (Tabela 2). O cálculo de GD a partir das titulações condutimétricas é feito a partir da equação 1 e os resultados totais obtidos nos diferentes ensaios estão listados na Tabela 2. 


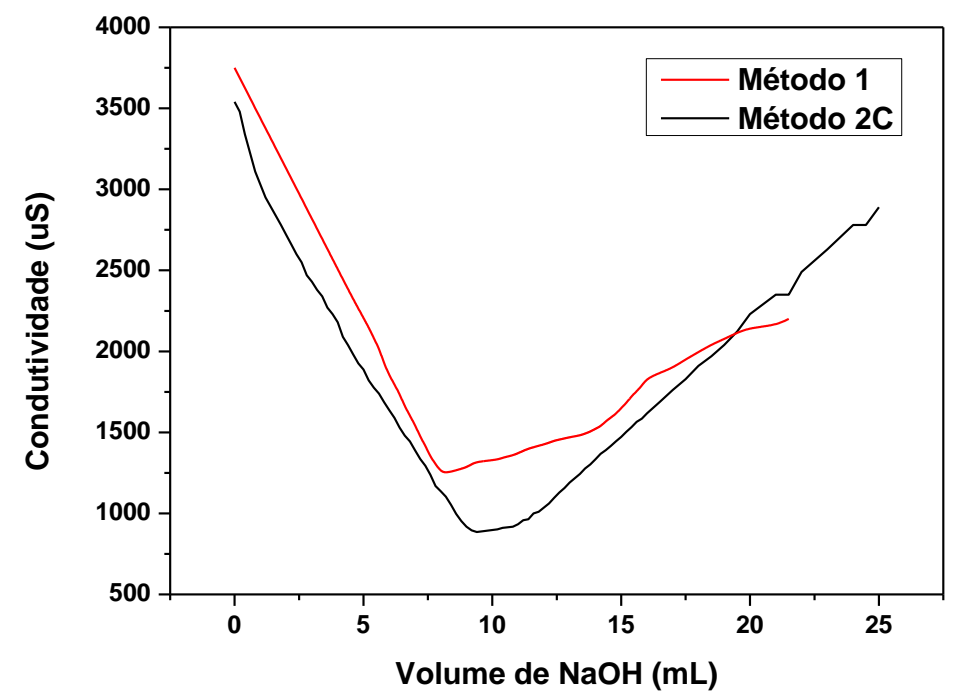

Figura 2. Curvas de titulação condutimétrica das amostras de quitosana.

$\% \mathrm{GD}=16,1 \mathrm{X}[\mathrm{BASE}] \mathrm{X}(\mathrm{V} 2-\mathrm{V} 1) / \mathrm{M}$

Equação 1

Onde equação 1, o GD é o grau médio de desacetilação, $\mathrm{V}_{1}$ é o volume de base usado para a neutralização de $\mathrm{HCl}$ em excesso $(\mathrm{mL}) ; V_{2}-V_{1}$ é o volume de base usado para a neutralização dos grupos ácidos de quitosana $(\mathrm{mL})$, [base] é a concentração da base usada e $m$ é a massa da amostra de quitosana. Com relação à confiabilidade deste método potenciométrico, Santos e colaboradores [10] demonstraram que os resultados obtidos por este método coincidem com os obtidos pela técnica quantitativa de espectroscopia de $\mathrm{RMN}^{1} \mathrm{H}$.

Tabela 2. Condições experimentais e grau de desacetilaçao médio (GD) obtido em cada método de desacetilaçao.

\begin{tabular}{|c|c|c|c|c|c|c|c|}
\hline & & $\begin{array}{l}\text { Concentra } \\
\text { ção de } \\
\text { base } \\
\left(\% \mathrm{~m} \cdot \mathrm{m}^{-1}\right)\end{array}$ & $\begin{array}{c}\text { Concentraçã } \\
\text { o de etanol } \\
\left(\% \mathrm{~m} \cdot \mathrm{m}^{-1}\right)\end{array}$ & $\begin{array}{c}\text { Concentração } \\
\text { de } \\
\text { monoetilenogli } \\
\text { col } \\
\left(\% \mathrm{~m} \cdot \mathrm{m}^{-1}\right)\end{array}$ & $\begin{array}{c}\text { Temperatu } \\
\text { ra } \\
\left({ }^{\circ} \mathrm{C}\right)\end{array}$ & $\begin{array}{l}\text { Tempo } \\
\text { de } \\
\text { refluxo } \\
(\mathrm{h})\end{array}$ & $\begin{array}{c}\mathrm{G} \\
\mathrm{D} \\
(\% \\
)\end{array}$ \\
\hline $\begin{array}{l}\text { Método 1- } \\
\text { Solução } \\
\text { aquosa de } \\
\mathrm{NaOH}\end{array}$ & & 50 & - & - & 110 & 10 & 79 \\
\hline Método & $2 \mathrm{~A}$ & 5 & 47 & 48 & 87 & 6 & 0 \\
\hline $2-$ & $2 B$ & 15 & 42 & 43 & 87 & 6 & 0 \\
\hline $\begin{array}{l}\text { Soluçao } \\
\text { não } \\
\text { aquosa } \\
\text { de KOH }\end{array}$ & $2 \mathrm{C}$ & 27 & 22 & 51 & 110 & 6 & 30 \\
\hline
\end{tabular}


Os valores de GD obtidos nos experimentos demonstram a maior eficiência do método 1 para a obtenção de quitosana. Embora a literatura descreva a possibilidade de se utilizar solução não aquosa de $\mathrm{KOH}$ a $50 \%\left(\mathrm{mxm}^{-1}\right)$, etanol e etilenoglicol $25 \%\left(\mathrm{mxm}^{-1}\right)$, em refluxo de 6 horas para obtenção de quitosana altamente desacetilada [3], nos experimentos realizados não foi possível solubilizar $\mathrm{KOH}$ a $50 \%$ em massa para mistura $25 \%$ de cada um dos solventes, motivo pelo qual se trabalhou com concentrações variáveis de $\mathrm{KOH}$ entre 5 e $27 \%$ em massa. Com relação às proporções entre etanol e monoetilenoglicol, o aumento de até $51 \%$ em massa deste segundo reagente teve como finalidade o aumento do ponto de bolha, uma vez que em ensaios anteriores não se conseguia temperatura maior que $90^{\circ} \mathrm{C}$. Não foi possível isolar a variável responsável pela desacetilação de $30 \%$ obtida no método 2 , uma vez que se alterou tanto proporções dos reagentes como temperatura de refluxo. De qualquer modo, 30\% de desacetilação é um resultado insatisfatório e o método deve ser aprimorado, mantendo-se em vista o tempo reduzido de refluxo, que segundo os resultados de Tolaimate et al [3], é o diferencial em relação ao método 1, não somente pela economia de energia mas principalmente por reduzir a degradação do biopolimero.

A caracterização qualitativa da quitosana obtida pelo método 1, com GD de $79 \%$ foi realizada por espectroscopia na região do Infravermelho (Figura 3) e apresentou as bandas características [10, 18]: estiramento axial de $\mathrm{OH}$ entre 3440 a $3480 \mathrm{~cm}^{-1}$, a qual aparece sobreposta à banda de estiramento $\mathrm{N}-\mathrm{H}$; deformação axial de $\mathrm{C}=\mathrm{O}$ de amida I (entre 1661 a $1671 \mathrm{~cm}^{-1}$ ); deformação angular de N-H (entre 1583 a $1594 \mathrm{~cm}^{-1}$ ); deformação angular simétrica de $\mathrm{CH}_{3}$ (entre 1380 a $1383 \mathrm{~cm}^{-1}$ ); deformação axial de - $\mathrm{CN}$ de amida (por volta de $1425 \mathrm{~cm}^{-1}$ ) e deformação axial de - CN de grupos amino (entre 1308 a $1380 \mathrm{~cm}-1$ ), além de bandas de estruturas polissacarídicas na região de $890-1156 \mathrm{~cm}^{-1}$. A existência das bandas pertencentes aos grupos amino comprovam que a quitina sofreu desacetilação, com a perca de grupamentos acetamido de sua estrutura. Porém, mesmo no espectro de infravermelho da quitosana verifica-se que há uma banda relativa ao grupo acetamida. Isso ocorre, pois mesmo com a desacetilação, ainda há a presença de alguns grupamentos acetamida remanescentes. 


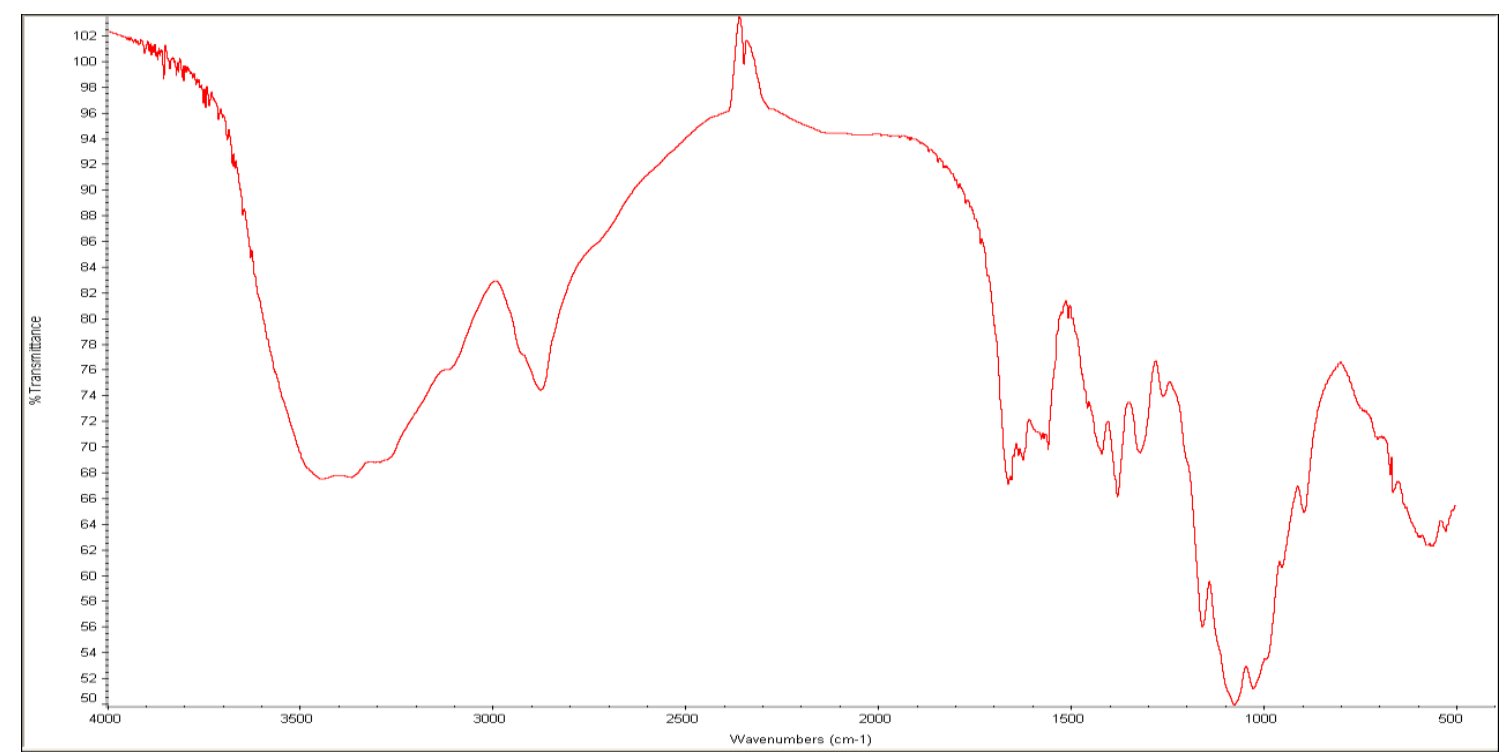

Figura 3: Espectro de absorção na região do Infravermelho (IV) da amostra de quitosana com GD de $79 \%$.

Devido ao caráter higroscópico da quitosana é normal que ocorra absorção de umidade durante a armazenagem e quitosanas comerciais costumam exibir teor de umidade menor que 5\% [19]. Para amostras de quitosana obtida pelos dois métodos de desacetilação testados aqui, aquoso e não aquoso, obteve-se experimentalmente teores de umidade próximos de $3 \%$ e $4 \%$, respectivamente.

\section{CONCLUSÃO}

Os resultados obtidos até o momento apontam que variações ainda podem ser adotadas nos métodos amplamente utilizados para as etapas de desmineralização e desproteinação, sendo que se observou que a eficiência destas etapas é muito próxima de $100 \%$, o que sugere que mesmo reduzindo-se a utilização de ácido e base nestas etapas é possível obter quitina dentro de valores aceitáveis com relação à presença de minerais e proteínas. Com relação à desacetilação da quitosana percebeu-se a exigência de uso de altas concentrações de álcali, onde para o método de desacetilação em soluções não aquosas não houve desacetilação detectável por potenciométria abaixo de $27 \%$ em massa de $\mathrm{KOH}$. O trabalho ainda em andamento deverá delinear a partir destes resultados preliminares a melhor combinação de concentração de base, tempo e temperatura reacionais e averiguar também a influência do método de desacetilação sobre outras características, como viscosidade, solubilidade e degradação do biopolímero, além do grau de desacetilação já comparado. 


\section{REFERÊNCIAS BIBLIOGRÁFICAS}

1. THE STATE OF WORLD FISHERIES AND AQUACULTURE. FOOD AND AGRICULTURE ORGANIZATION OF THE UNITED NATIONS. ROMA, 2009. DISPONÍVEL EM: WWW.FAO.ORG.

2. HENNIG, E. L. Utilização de Quitosana Obtida de Resíduos de Camarão para Avaliar a Capacidade de Adsorção de Íons Fe3+. RIO GRANDE DO SUL, 2009.

3. TOLAIMATEA, A; DESBRIERESB, J; RHAZIA, M; ALAGUIC, A. Contribution to the preparation of chitins and chitosans with controlled physico-chemical properties. Polymer 2003.

4. SHAHIDI, F; SYNOWIECKI, J. Isolation and Characterization of Nutrients and Value-Added Products from Snow Crab (Chinoecetes opilio) and Shrimp (Pandalus borealis) Processing Discards. J Agric Food Chem. 1991. p. 1527-1532.

5. JUANG, R; WU, F; TSENG, R. Solute adsorption and enzyme immobilization on chitosan beads prepared from shrimp shell wastes. Bioresource Technology. 2001. p. 80, 187-193.

6. CARVALHO, T. V. Biomateriais à Base de Quitosana de Camarão e Bactérias para Remoção de Metais Traços e Petróleo. FORTALEZA, 2006.

7. ROSA, S. Adsorção de Corantes Reativos Utilizando Sal quaternário de Quitosana como Adsorvente. FLORIANÓPOLIS, 2009.

8. ANTONINO, N. A. Otimização do Processo de Obtenção de Quitina e Quitosana de Exoesqueletos de Camarões Oriundos da Indústria Pesqueira Paraibana. PARAÍBA, 2007.

9. BROUSSIGNAC, P. Chim Ind Genie Chim. 1968. p. 99, 1241.

10. DOS SANTOS, J. E; SOARES, J. P; DOCKAL, E. R; CAMPANA FILHO, S. P; CAVAlHEIRO, E. T. G. Caracterização de Quitosanas Comerciais de Diferentes Origens Polímeros: Ciência e Tecnologia. 2003. p. 13 (4), 242-249.

11. RAO, M. S; STEVENS, W. F. Fermentation of Shrimp Biowaste under Different Salt Concentrations with Amylolytic and Non-Amylolytic Lactobacillus Strains for Chitin Production. Food Technol. Biotechnol. 2006. p. 44, 83-87.

12. RAO, M. S; STEVENS, W. F. Chitin production by Lactobacillus fermentation of shrimp biowaste in a drum reactor and its chemical conversion to chitosan. Journal of Chemical Technology and Biotechnology. 2005. p. 80, 1080-1087.

13. DUAN, S; LI, L; ZHUANG, Z; WU, W; HONG, S; ZHOU, J.. Improved production of chitin from shrimp waste by fermentation with epiphytic lactic acid bacteria. Carbohydrate Polymers. 2012. p. 89, 1283- 1288

14. MACQUARRIE, D. J; HARDY J. E. Applications of Functionalized Chitosan in Catalysis. 2005.

15. GUIBAL, E. Interactions of metals ions with chitosan-based sorbents: a review. Separation and Purification Technology. 2004. p. 38, 43-74.

16. CHIESSIA, E; PISPISA, B. Polymer-supported catalysis: Oxidation of catecholamines by $\mathrm{Fe}$ (III) and $\mathrm{Cu}$ (II) complexes immobilized to chitosan. Journal of Molecular Catalysis. 1994. p. 87, 2-3, 177-193.

17. JUANG, R; WU, F; TSENG, R. Solute adsorption and enzyme immobilization on chitosan beads prepared from shrimp shell wastes. Bioresource Technology. 2001. p. 80, 187-193.

18. COSTA, E. S. J. MANSUR, H. S. Preparação e Caracterização de Blendas de Quitosana/Poli (Álcool Vinílico) Reticuladas Quimicamente Com Glutaraldeído para 
Aplicação em Engenharia de Tecido. QUÍMICA NOVA. 2008. Vol. 31, p. 6, 14601466.

19. NESSAA, F. MASUMB, S. M. ASADUZZAMANA, M. ROY, S. K. HOSSAINA, M. M. JAHANC, M. S. A Process for the Preparation of Chitin and Chitosan from Prawn Shell Waste. BANGLADESH J. SCI. IND. RES, 2010. p. 323-330. 